\title{
Effects of Feedback on Residential Electricity Consumption: A Literature Review
}

\author{
Barbara C. Farhar \\ Colleen Fitzpatrick
}

January 1989

Prepared under Task No. BE911041

Solar Energy Research Institute

A Division of Midwest Research Institute

1617 Cole Boulevard

Golden, Colorado 80401-3393

Prepared for the

U.S. Department of Energy

Contract No. DE-AC02-83CH10093 


\section{CONTENTS}

Page

INTRODUCTION $\ldots \ldots \ldots \ldots \ldots \ldots \ldots \ldots \ldots \ldots \ldots \ldots \ldots \ldots \ldots \ldots \ldots \ldots \ldots \ldots$

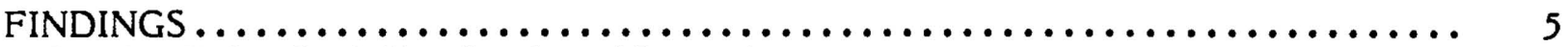

Studies Using Both Feedback and Incentives $\ldots \ldots \ldots \ldots \ldots \ldots \ldots \ldots \ldots \ldots \ldots$

Studies Using Goal Setting $\ldots \ldots \ldots \ldots \ldots \ldots \ldots \ldots \ldots \ldots \ldots \ldots \ldots \ldots \ldots \ldots \ldots \ldots$

Studies on Cost Information Feedback ......................... 10

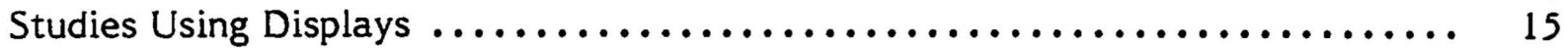

Other Related Studies ................................... 16

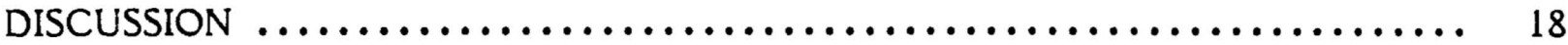

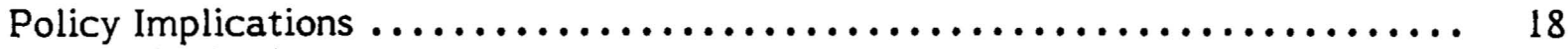

Research Needs .......................................... 18

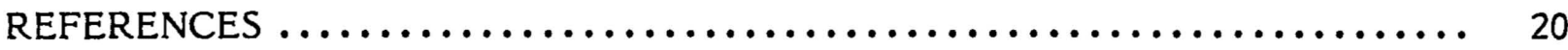




\section{INTRODUCTION}

Purchasing energy for one's home is like shopping in a store without price tags. You select what you want and pay a total amount without ever knowing how much each item cost. A utility bill ordinarily provides some information about the number of units of electricity or natural gas consumed and a total amount due. Customers usually receive no information on how much various energy users (such as refrigerators or waterbeds) cost to operate. They don't receive information on their weather-adjusted heating or cooling usage. If customers attempt to conserve energy, they receive little or no feedback on how well they did.

Yet it would be sensible to expect customers to change their energy consumption behavior if they had information on which to base decisions about it. Price is known to affect demand to some extent. If customers could tell how much they were being charged for energy users, they could decide how they wanted to spend their energy dollars.

Utility companies have not expressed much interest in how information feedback might affect energy consumption. For a utility to reprogram its billing algorithms and to collect and maintain the data bases necessary to provide accurate disaggregated information feedback would indeed be a costly enterprise. Such costs are unlikely to be approved by utility regulators in the absence of evidence that they would result in substantial conservation. The evidence in hand on the role of information feedback in reducing energy consumption is scanty at best.

Various research groups have conducted studies to assess the effects of feedback on residential electricity consumption. Several investigators analyzed the effects of feedback alone or in conjunction with other factors, such as goal setting and monetary incentives. Findings show that feedback alone and in conjunction with other factors can be effective in reducing electricity consumption. No studies were found that investigated the use of monthly utility bills as a means of providing feedback. One pilot study on a household energy report to accompany monthly bills used monthly utility billings as a means of feedback (Layne et al. 1987). Another study investigated a pilot disaggregated electric usage analysis conducted by a utility (Morgan 1988).

Table 1 summarizes the key characteristics in the studies discussed. This review briefly describes the design and findings of research conducted in various parts of the country investigating the effects of feedback as a single variable or in combination with other factors.

The studies reviewed are organized into categories according to key elements of feedback that they investigated. These are:

- Studies using both feedback and incentives

- Studies using goal setting with feedback

- Studies on cost information feedback

- Studies using displays for feedback

- Other related studies. 
Table 1. Characteristics of Feedback Used (Concluded)

\begin{tabular}{|c|c|c|c|c|c|}
\hline Study & $\begin{array}{c}\text { Frequency } \\
\text { of } \\
\text { Feedback }\end{array}$ & $\begin{array}{l}\text { Over What } \\
\text { Time } \\
\text { (Location) }\end{array}$ & $\begin{array}{l}\text { For What } \\
\text { Energy } \\
\text { End Uses }\end{array}$ & $\begin{array}{c}\text { Form } \\
\text { of } \\
\text { Feedback }\end{array}$ & $\begin{array}{l}\text { Savings } \\
\text { Achieved } \\
\text { by } \\
\text { Feedback }\end{array}$ \\
\hline $\begin{array}{l}\text { Winett, } \\
\text { Kaiser, and } \\
\text { Haberkorn } \\
(1976-77)\end{array}$ & $\begin{array}{l}1 \text { time/day } \\
\text { for } 6 \text { weeks }\end{array}$ & $\begin{array}{l}\text { March-May } \\
\text { (Lexington, } \\
\text { KY) }\end{array}$ & $\begin{array}{l}\text { Lighting, appli- } \\
\text { ances, and air } \\
\text { conditioning }\end{array}$ & $\begin{array}{l}\text { Notes } \\
\text { left on } \\
\text { door }\end{array}$ & $\begin{array}{l}10 \% \text { to } 15 \% \\
\text { reduction } \\
\text { (included } \\
\text { info.) }\end{array}$ \\
\hline $\begin{array}{l}\text { Winett et al. } \\
\text { (1978) }\end{array}$ & $\begin{array}{l}1 \text { time/week } \\
\text { for } 4 \text { weeks }\end{array}$ & $\begin{array}{l}\text { August } \\
\text { (TX) }\end{array}$ & Air conditioning & $\begin{array}{l}\text { Meter } \\
\text { reading }\end{array}$ & $\begin{array}{l}\text { None } \\
\text { consumption } \\
\text { comparisons }\end{array}$ \\
\hline $\begin{array}{l}\text { Winett et al. } \\
(1978-79)\end{array}$ & $\begin{array}{l}\text { Every day for } \\
5-6 \text { weeks }\end{array}$ & $\begin{array}{l}\text { June-July } \\
\text { (Greenbelt, } \\
\text { MD) }\end{array}$ & Air conditioning & $\begin{array}{l}\text { Notes left } \\
\text { at door }\end{array}$ & $\begin{array}{l}7 \% \text { to } 20 \% \\
\text { reduction }\end{array}$ \\
\hline $\begin{array}{l}\text { Winett, } \\
\text { Neale, and } \\
\text { Grier (1979) }\end{array}$ & $\begin{array}{l}\text { Daily for } 28 \\
\text { consecutive } \\
\text { days }\end{array}$ & $\begin{array}{l}\text { March } \\
\text { (Washington, } \\
\text { DC suburbs) }\end{array}$ & $\begin{array}{l}\text { Heating, cooking, } \\
\text { air conditioning, } \\
\text { refrigeration, } \\
\text { and lights }\end{array}$ & $\begin{array}{l}\text { Self-moni- } \\
\text { toring; notes } \\
\text { left at door }\end{array}$ & $\begin{array}{l}7 \text { to } 11 \% \\
\text { reductions }\end{array}$ \\
\hline \multirow[t]{2}{*}{$\begin{array}{l}\text { Winett et al. } \\
\text { (1982) }\end{array}$} & $\begin{array}{l}\text { Daily for } \\
35 \text { days }\end{array}$ & $\begin{array}{l}\text { Winter } \\
\text { (Blacksburg, } \\
\text { VA) }\end{array}$ & $\begin{array}{l}\text { Heating, cooking, } \\
\text { lights, and } \\
\text { refrigeration }\end{array}$ & $\begin{array}{l}\text { Notes left } \\
\text { at door }\end{array}$ & $\begin{array}{l}17 \% \text { less } \\
\text { than con- } \\
\text { trol group }\end{array}$ \\
\hline & $\begin{array}{l}\text { Daily for } \\
30 \text { days }\end{array}$ & $\begin{array}{l}\text { Summer } \\
\text { (Salem, } \\
\text { VA) }\end{array}$ & $\begin{array}{l}\text { Cooking, air } \\
\text { conditioning, } \\
\text { lights, and } \\
\text { refrigeration }\end{array}$ & $\begin{array}{l}\text { Notes left } \\
\text { at door }\end{array}$ & $\begin{array}{l}19 \% \text { reduc- } \\
\text { tion from } \\
\text { baseline }\end{array}$ \\
\hline
\end{tabular}




\section{FINDINGS}

\section{$\underline{\text { Studies Using Both Feedback and Incentives }}$}

Four studies were located which explored the use of information feedback along with monetary incentives. These were: (a) Kohlenberg, Phillips, and Procter (1976), (b) Winett, Kaiser, and Haberkorn (1976-77), (c) Hayes and Cone (1977), and (d) Winett, et al. (1978).

Kohlenberg, Phillips, and Proctor (1976) investigated variables influencing consumers in reducing peak demand energy consumption, which tested the effects of information, feedback, and feedback plus monetary incentives on electricity consumption. The participants in this study were three Seattle, Wash., households, none of which were electrically heated; each had an electric stove, dryer, dishwasher, and water heater.

The researchers installed $24-\mathrm{h}$ chart recorders in each residence to monitor electrical energy consumption in 15-min intervals. An experimenter informed the households about peaking problems and their relationship to the raising of Ross Dam (the subject of local controversy). Participants were asked to avoid using too much power at any one time and to try reducing peaking. Participants received a list of $100-\mathrm{W}$ light bulb equivalents for the power ratings of the electrical appliances in their homes.

Feedback consisted of a current-sensitive relay installed in each house. When current levels reached $90 \%$ of the peak levels, which had been recorded 2 weeks prior during a baseline period, a 40-W bulb located in the kitchen was triggered. Each household received explanations on how the signal light could be used for helping to reduce peak consumption.

The investigators asked each household to make special efforts to demonstrate that it was possible to reduce peaking. As an incentive, participants received double the prorated amount of the electricity bill for a 2-week period for a $100 \%$ reduction in peaking, $200 \%$ for a $75 \%$ reduction, $100 \%$ for a $50 \%$ reduction, and $50 \%$ for a $25 \%$ reduction. Subjects received instructions on how to compute peaking reductions from a chart recorder installed previously. The research spanned a 3 -month period from early January through March. Weekly data collection consisted of an experimenter recording electricity consumption on a device installed for recording normal power use.

Findings showed that information alone had little effect. Feedback alone seemed to be effective but only to a small magnitude. The greatest effect on reducing electricity consumption was in the incentive-feedback condition--resulting in a $50 \%$ reduction in peaking. The study concluded that although feedback was important in producing changes in peak energy use behavior, feedback combined with a payment condition had a greater effect. Removal of the experimental conditions resulted in a return to previous consumption patterns.

Winett, Kaiser, and Haberkorn (1976-77) investigated feedback, information, and a rebate system in 12 ( 6 control and 6 experimental) apartments where electricity was used for lighting, appliances, and air conditioning. The study, conducted over a 6-week period from March to May, with temperatures varying from $84^{\circ}$ to $27^{\circ} \mathrm{F}$, involved students or recent college graduates in Lexington, $\mathrm{Ky}$., who tended to be consistently away from their apartments most of the day and sporadically away on weekends. 
Information sheets, included in letters describing the experimental procedures, indicated six ways to conserve electricity:

- Reduce the use of major appliances

- Moderate the use of air conditioning

- Close the drapes on warm sunny days

- Use no air conditioning when windows are open

- Reduce the use of hot water

- Turn out unnecessary lights.

Following a 1-week baseline period, all six experimental units were placed on a 1-week rebate schedule (Monday-Sunday), which provided payments of $\$ 2$ for a 5\%-9\% reduction in electricity consumption, $\$ 3$ for a $10 \%-20 \%$ reduction, $\$ 5$ for a $21 \%-30 \%$ reduction, and $\$ 7$ for a reduction greater than $30 \%$. This rebate system represented a price reduction in electricity consumption between $300 \%$ and $400 \%$. A daily note left at the apartment following the daily meter reading by a research assistant provided the percentage of increase or decrease in electricity consumption, average increase or decrease for the week, and expected earnings.

The investigators then placed three experimental units on a rebate system, which consisted of payments that were $50 \%$ of the first system. The remaining three experimental units received only daily feedback notes. All experimental units received feedback and information sheets for a period of either 4 or 5 weeks without a rebate system.

The study found daily feedback, preceded by a rebate system representing a price reduction between $300 \%$ and $400 \%$, resulted in a reduction in apartment electricity consumption averaging from $10 \%-15 \%$. However, feedback was not effective during very warm days when air conditioning was used frequently. The reduction of the experimental group each week exceeded the control group's reduction. The study did not investigate the effects of feedback without information sheets.

Hayes and Cone (1977) examined the effects of payments, information, and feedback on levels of electrical energy consumption. This study differed from previous studies by looking at all three variable classes (feedback alone, feedback plus payment, and payment alone) separately and in various combinations. The study was conducted from January to May, involving four units from a housing complex for married students at West Virginia University. Electricity was used for cooking, refrigeration, and ventilation fans. Meter readings, taken for 8 to 13 days, provided a baseline electricity consumption level.

For the first week, all four units received cash payments according to a percent reduction in weekly electricity consumption compared to baseline levels. The study implemented the following payment schedule:

- $\$ 3$ for a $10 \%-19 \%$ reduction

- $\$ 6$ for a $20 \%-29 \%$ reduction

- \$9 for a $30 \%-39 \%$ reduction

- $\$ 12$ for a $40 \%-49 \%$ reduction

- $\$ 15$ for a $50 \%$ or more reduction.

Later phases of the study reduced these levels to $83 \%, 50 \%, 25 \%$, or $10 \%$ of the original dollar amount in two of the four units. 
Feedback consisted of a flier left in the mailbox every day, which contained the following (in dollars and cents):

- Amount of electricity consumed the previous day

- Amount of electricity consumed so far for the week

- Amount of electricity that would be consumed for the week at that rate of consumption

- The percentage above or below baseline levels.

Information consisted of a poster describing ways to reduce electricity consumption and the amount of energy consumed per year for most common household electrical devices.

The study found that paying consumers for reduced energy consumption was the most effective of the three procedures resulting in an average $33 \%$ reduction in electricity consumption from baseline levels. The combined effect of feedback and $100 \%$ payment was no greater than $100 \%$ payment alone. Feedback alone was studied in only one of the four units. In this case, feedback produced a $15 \%$ to $21 \%$ reduction in baseline electricity consumption during a 2-week period.

Winett, et al. (1978) reported that of high monetary rebates, weekly written feedback, or conservation information, only a high rebate condition significantly reduced electricity consumption--by about $12 \%$. This study involved 12 Texas households whose primary use of electricity was for air conditioning. The period of the study was from June to August.

After a 2-week period of meter readings to establish a baseline consumption level, investigators randomly assigned each household to one of five groups:

- High rebate: received rebates up to $30 \notin$ for each $1 \%$ reduction in weekly $\mathrm{kWh}$ usage plus feedback information

- Low rebate: received $1.3 \notin$ payment for each $\mathrm{kWh}$ reduced plus feedback information

- Feedback: received copies of weekly meter readings and mailings comparing each week's use with the previous summer's average

- Information: received booklets on household energy conservation tips and information on how to compute the electric bill

- Control: received information booklets at the end of 4 weeks.

Results indicated that overall, only the high rebate system (which included feedback) resulted in substantial reductions (14\%-16\%) in electricity usage. Information alone may have actually increased usage. Weekly feedback and information were ineffective in reducing electricity consumption.

Summary. The studies exhibit a consistent pattern of findings that feedback plus monetary incentives worked well in reducing energy consumption. Information on consumption by itself had little effect.

\section{Studies Using Goal Setting}

Four studies were located which investigated using feedback in combination with setting goals to reduce consumption. These were: (a) Becker (1978), (b) Winett, et al. (1978-79), (c) Winett, Neale, and Grier (1979), and (d) Winett, et al. (1982). 
Becker (1978) found that feedback in relationship to goal setting significantly reduced energy consumption. This study occurred from June through August in central New Jersey. It consisted of 100 families residing in townhouses. The investigator assigned each household to either a control or feedback group. Research staff recorded the household's meter readings over a 9-week period to determine average daily consumption. The investigator used the average daily consumption of each household in the feedback group to produce a predicted average daily consumption value.

Each household received an information sheet listing various appliances found in the home and the amount of electricity each consumed. The researcher asked each family in both the feedback and control groups to adopt either a fifficult (20\% reduction) or an easy ( $2 \%$ reduction) conservation goal. Research assista...s recorded the meter readings from each household on Monday, Wednesday, and Friday mornings for 3 weeks; after each meter reading, on the same day, the feedback group received data on a plastic chart attached to the outside of the kitchen window facing inward, reflecting actual reduction in electricity consumption with respect to the reduction goal of $20 \%$ or $2 \%$. The families assigned to the $20 \%$ goal and given feedback consumed the least amount of electricity and was the only group that used significantly fewer $\mathrm{kWh}$ than the control group. The $20 \%$ feedback group used $13 \%$ less electricity than the control group and the $2 \%$ feedback group used $5 \%$ less. The results pointed out the importance of setting difficult conservation goals and giving feedback on performance with respect to the goals.

Winett, et al. (1978-79), in a replication of prior research, studied the effects of feedback alone. This study, conducted from April to September, involved 121 households in Greenbelt, Md., using electricity for air conditioning. Researchers assigned households to one of four conditions:

- Control

- Individual feedback

- Group feedback

- Individual-group feedback.

Research assistants read the electricity meters for all households every day for 22 to 29 days to establish baseline levels. Investigators asked each feedback household to select a reduction goal--resulting in an average goal of $5 \%$.

Individual feedback consisted of $\mathrm{kWh}$ used the previous day and the percentage of increase or decrease based on the control group's baseline and prior day's use. The feedback form indicated whether the reduction was better than the individual household's chosen goal. Group feedback was based on figures for the total group's kWh usage, reflecting a group percentage of increase or decrease. Participants received feedback presented on color-coded forms with a series of smiles or frowns depicting different levels of increase or decrease in electricity consumption.

Findings demonstrated that group feedback yielded negligible reductions. Where individual feedback was used alone or in combination with group feedback, both approaches reduced consumption by 7\%-20\%, with no difference in the effectiveness of the 2 feedback methods found. The study concluded that individual feedback may be the most efficacious method.

This study also provided ideas on how to offer feedback, such as the use of energy monitors that display $\mathrm{kWh}$ used, cost at current rates of use, and cumulative cost. The investigators also suggested that consumers be taught how to monitor their own conventional electricity meters persistently and reliably. 


\section{S:P}

Winett, Neale, and Grier (1979) evaluated a more practical feedback procedure of selfmonitoring meter reading. With minimal training and prompting, self-monitoring consumers were found to be highly reliable and persistent meter readers. This study, conducted from January to May in an all-electric townhouse community near Washington, DC, involved 45 households assigned to a feedback, self-monitoring, or volunteer comparison group. A fourth group consisted of a nonvolunteer comparison group. Investigators established a 3-week baseline usage level in January for each household.

The feedback and self-monitoring groups attended separate meetings where they were given conservation information emphasizing thermóstat control and a booklet showing savings from retrofitting and better use of appliances. After the meetings, each feedback household received a feedback sheet placed on the doorstep every day for 28 consecutive days. The feedback sheet replicated the form used in the Winett, et al. (1978) study, which stated use in terms of the household's reduction goal. The self-monitoring households received the same information as the feedback group and, in addition, were taught to read their own electricity meters. After being instructed to determine if the prior day's use had been above or below expected levels, the self-monitoring group received a note on the doorstep for 28 days that showed expected use for the prior day. Research staff read the electricity meters every day. The self-monitoring households meter readings were compared to the staff's meter readings to determine reliability.

Results showed no significant differences between groups in baseline electrical use levels, although the nonvolunteer comparison group used more $\mathrm{kWh}$ per household than the other three groups. During the intervention and subsequent 4- and 6-week follow-up periods, the feedback group reduced electricity consumption by about $11 \%$ and the selfmonitoring group by about $7 \%$, compared with the combined comparison group.

Reductions found in this study were primarily attributed to thermostat setting behavior. Analysis of cost-benefits found that each feedback household saved an average $\$ 44$ and each self-monitoring household saved an average \$26 from expected expenditures based on the comparison group's use during the 14 weeks of intervention and follow-up.

Winett, et al. (1982) found feedback and/or videotape modeling programs reduced electricity consumption in all-electric townhouses or apartments. This research consisted of two studies, one conducted during the winter in Blacksburg, Va. $(\mathrm{N}=83)$ and the other during the summer in Salem, Va. $(\mathrm{N}=54)$. The study placed each household in one of the following conditions:

- Feedback and discussion

- Information and modeling

- Information and discussion

- Feedback and modeling

- Information and discussion

- Control.

The researchers provided households in the feedback group with a thermostat change schedule card, placed near the thermostat, which called for a $1^{\circ} \mathrm{F}$ reduction in thermostat setting per week for 4 weeks. Feedback, given for 35 days in the winter and 30 days in the summer, provided daily information indicating the percentage of increase or decrease from baseline levels. Feedback replicated the form used in the Winett, Neal, and Grier (1979) study. The study included weather-adjusted data and asked each participant to reduce electricity consumption by $15 \%$ with each signing a form agreeing to attempt reaching this goal. Videotape modeling consisted of two 20-min videotapes 
depicting various ways of coping with changes in thermostat settings with demonstrations on using setbacks. Emphasis was placed on thermostat setbacks.

Results of the winter study indicated that groups receiving feedback and/or modeling consumed about $12 \%$ less electricity than the information and discussion group and about $17 \%$ less than the control group. During intervention, both feedback and modeling groups reduced their baseline electricity for heating consumption by about $23 \%$ compared to baseline levels. The overall results indicated that feedback and/or modeling were effective in reducing electricity consumption by thermostat control (particularly set-backs) with a warmer follow-up period demonstrating some evidence for maintenance of effect.

Results of the summer study indicated that, during intervention, the feedback group reduced electricity consumption by $19 \%$ and the feedback-modeling group reduced consumption by $22 \%$, compared to baseline levels. During the follow-up phase, both the feedback and feedback-modeling groups maintained reduction compared to baseline levels by $29 \%$ and $37 \%$, respectively.

Summary. Only one of the four studies reviewed investigated the role of goal-setting in combination with feedback in reducing electricity consumption. This study found that setting difficult conservation goals and providing feedback on performance with respect to the goals resulted in the most energy saved. The other three studies used goal-setting as the context within which feedback information was provided, thereby not testing the effect of goal-setting itself.

The other three studies found the feedback tailored to the individual household rather than to a group of households, feedback provided by an external source rather than selfmonitoring, and feedback that included suggestions about how to cope with reduced consumption were more effective. These results obtained in the context of conservation goal-setting.

\section{Studies on Cost Information Feedback}

Five studies were found that included giving feedback on costs alone or on both $\mathrm{kWh}$ consumption and costs. These were (a) Palmer, Lloyd, and Lloyd (1977), (b) Morgan (1988), (c) Ramey-Smith and Gagnon (1979), (d) Bittle, Valesano, and Thaler (1979), and (e) Layne, et al. (1987).

Palmer, Lloyd, and Lloyd (1977) studied the effects of daily prompts and feedback on electricity consumption in four households in Des Moines, lowa. Investigators established baseline levels of electricity consumption at various intervals throughout the study. Research staff collected data from February to May for a total of 106 days. All households used electric heat.

The study involved five conditions:

- Feedback:

Each night, a card (taped to the inside of the front storm door) showed electricity consumption for the day compared to consumption for a previous baseline period.

- Cost information:

Added to the feedback was the expected monthly bill projected from the mean baseline consumption. The difference between the two was identified as the amount of money that would be saved or wasted if that day's consumption were maintained for 30 days. 
- Daily prompt:

- Prompt plus feedback:

- Government prompt:
Each night, one of a series of eight prompts was taped to the inside of the storm door.

Each night, feedback with a prompt on the back was taped to the door.

A personal letter was mailed to each family from the Iowa Office of Energy.

Results showed that introduction of cost information appeared to have the greatest impact on reducing consumption. The investigators did not analyze the magnitude of this reduction. The power company provided comparable 3-month consumption data for preexperimental, experimental, and postexperimental years. In all households, electricity consumption was lower, by an average of $16 \%$, during the experimental period than during the preexperimental period. Three of the households' (one moved from the area) electricity consumption averaged $9 \%$ lower for the postexperimental period than the preexperimental period.

The study demonstrated the effectiveness of prompting and feedback techniques in reducing electricity consumption. The study also pointed out that the local power company seemed to encourage high rates of electricity consumption by charging a lower $\mathrm{kWh}$ rate for increased usage resulting in proportionately smaller money savings for large reductions in usage, indicating that it would be more efficient to reverse the billing procedures by charging increasingly more for greater consumption.

Morgan (1988) evaluated a pilot electricity usage analysis for residential customers which Boston Edison piggybacked on its home energy audit program. The project, called EASYPlus, used proprietary software developed by ENERCOM, Inc. to collect data from households to use in a computer algorithm to produce monthly and annual usage analyses. The results were presented as bar charts showing electricity costs broken down by 13 end uses (such as refrigerator and clothes washer).

The EASY-Plus service was delivered in two different modes--(1) by an auditor in person at the end of the regular audit, and (2) by mail. The study tested customer behavioral response to the analysis results, which constituted feedback on their electricity use. Morgan completed an analysis of the actual electricity consumed in households receiving and not receiving the analyses. He found that households receiving the analyses saved about $7 \%$ more electricity than the average Boston Edison residential customer, although the findings should be viewed with caution due to limitations in sample size and other study problems. Additionally, Boston Edison found that the electricity usage analysis helped resolve high bill complaints.

Ramey-Smith and Gagnon (1979) studied cost feedback preferences in 18 metropolitan Washington, DC, households. The study did not describe the exact use of electric energy and some of the households used gas or oil in addition to electricity. Feedback consisted of an LED display device installed in each home, which indicated the dollar and cent cost of operating various appliances. Each household received feedback in one of the following ways:

- Cumulative: accumulated cost of electricity consumption for daily, weekly, or monthly periods

- Instantaneous: the rate of present usage and estimates on what the cost would be if consumption continued at that rate for 1 hour, 1 day, or 1 month 
the rate of usage based on the previous day's cost, which was used to estimate the energy cost for the following day, week, or month.

Results showed that daily and monthly cumulative feedback were the preferred forms of cumulative feedback, hourly instantaneous feedback was the preferred form of instantaneous feedback, and daily projected feedback was the preferred form of projected feedback.

When asked to choose a combination of feedback procedures, the majority of participants included some form of cumulative feedback. All participants having two energy sources expressed a need to have feedback presented in separate values reflecting the energy source. This study did not involve an analysis concerning the effects of feedback on energy consumption.

Bittle, Valesano, and Thaler (1979) reported that feedback efforts may be more effective if made when demands for energy were high. This study involved 30 rural southern Illinois households for which use of electrical energy was not determined. The study, conducted between June and September, involved three procedure phases:

- 12-day daily meter reading baseline period

- 42-day weekday meter reading with feedback for an experimental group and no feedback for a control group period

- 24-day reversal period during which feedback was provided to the previous no-feedback group and no feedback was provided to the previous feedback group.

Feedback cards, placed daily in the appropriate household's mailbox, contained date, number of $\mathrm{kWh}$ used, cost of $\mathrm{kWh}$ used on a particular day or weekend period, and the cumulative cost of electricity since the feedback period began.

During the first feedback phase, the feedback group used an average of $4 \%$ less electricity per day than the control group. During the second feedback phase, the feedback group consumed an average of $14 \%$ less electricity than when feedback was not given.

To determine if temperature change was the determining variable in decreasing consumption during the second feedback phase, a comparison was made of consumption rates in both feedback and no-feedback conditions on days when the temperature was comparable. This comparison clearly demonstrated that electricity consumption varied as a function of feedback regardless of average temperature highs. On days when temperatures ranged from $76^{\circ}$ to $80^{\circ} \mathrm{F}$, the rate of consumption averaged $30 \%$ less when feedback was given. On days when temperatures ranged from $81^{\circ}$ to $85^{\circ} \mathrm{F}, 86^{\circ}$ to $90^{\circ} \mathrm{F}$, and $91^{\circ}$ to $95^{\circ} \mathrm{F}$, the average consumption was about $15 \%$ lower when feedback was given.

Although this study found feedback related to reduced electricity consumption in general, a greater difference in consumption between feedback and no-feedback conditions was found when the need for electricity for cooling purposes was lowest. This indicates that feedback could be more effective in reducing consumption when needs are lower. The study further pointed out that efforts should be made to promote conservation habits at low-use times rather than at peak usage times.

Presenting contradictory findings, Bittle, Valesano, and Thaler (1979-80) later found that feedback was effective in restraining consumption in high consumers but had an opposite effect on medium and low consumers, suggesting that feedback efforts may be more 
effective if made when demands for energy are high. This study involved 353 households in a rural southern Illinois community conducted between June and August. Meter readings taken daily (Monday through Saturday) for 16 to 26 days determined baseline consumption levels. The study did not describe household uses of electricity.

Investigators assigned all households to one of four types of daily feedback conditions:

- Number of $\mathrm{kWh}$ used the previous day

- Cumulative number of $\mathrm{kWh}$ used since the first of the month

- Dollar and cents of electricity for the previous day

- Cumulative dollars and cents of electricity used since the first of the month.

The researchers then assigned one-fourth of the households in each group to a delay group, which began receiving feedback 10 days after the primary group. Feedback periods spanned 35 days for the primary group and 26 days for the delay group.

Research staff read the electric meters each Monday through Saturday morning. The staff calculated and then recorded consumption and cost on feedback cards delivered to each household. Each experimental group was divided into high, medium, and lower consumer groups based on a frequency distribution of mean daily consumption during the baseline period.

The weather became considerably warmer after the baseline consumption level was established; therefore, all the groups increased consumption over their baseline levels during the feedback phase of the study. The data were not weather-adjusted and thus the effects of feedback could not be determined by comparing consumption during feedback to baseline levels, although intergroup comparisons were made.

Intergroup comparisons revealed that feedback was effective in restraining electricity consumption for consumers who used large amounts of electricity. However, for lower consumers, feedback appeared to increase consumption. For high consumers, cumulative feedback was more effective than daily consumption feedback only. For medium consumers, cumulative feedback was more effective initially but tended to equalize as feedback continued. For lower consumers, cumulative feedback was least effective. The data in this study indicated that:

- Under extreme weather conditions, feedback was effective in restraining consumption in consumers who used large amounts of electricity.

- Daily cumulative feedback was more effective than daily noncumulative feedback.

- Feedback during extremely hot weather increased consumption in low to medium users.

Layne, et al. (1987) conducted a pilot study evaluating the effectiveness of a household energy report providing annual (not just monthly) weather-adjusted feedback data to electricity consumers. This study asserted that annual feedback was preferable in programs that were aimed at affecting the consumer's evaluation of retrofit investments (such as insulation or a new furnace). The feedback model used a monthly and annual report rather than more frequent feedback.

The research team developed a questionnaire and a prototype report called the Home Energy Report (HER) for use in conducting interviews with a nonrandomly selected sample $(\mathrm{N}=173)$ of all-electric households in central New Jersey. The interviews revealed that energy bills were used for at least two purposes beyond making monthly payments: 
- Checking on unusual months

- Evaluating conservation actions.

Both purposes required electrical consumption comparisons involving three methods:

- This versus recent months

- This month versus same month last year

- The highest this year versus the highest last year.

The study found optimum frequency of feedback dependent on the purpose for which it was used. Monthly feedback was needed for monitoring short-term changes and yearly feedback was better for larger and lasting changes such as those in family structures, major retrofits, or deliberate changes in management, asserting that a report with both types of feedback would enable people to make the largest number of inferences.

The investigators designed the HER under the assumption that weather-adjusted and cost-adjusted figures would help consumers sort out weather fluctuations and rate changes that affect their bills. However, they found that people were suspicious of or did not grasp the concept of weather-adjusted figures when they were presented without the corresponding actual figures. This indicates that it is better to give both actual and weather-adjusted figures together.

As part of the experiment, the HER presented a distinction between space heating from nonheating (such as water heating and cooking). The study found people reacted with skepticism and suspicion to this heating/nonheating division involving two separate issues:

- Some did not understand how this number could be known since there was only one utility meter.

- Some felt that their privacy was being invaded.

The final section of the HER showed the individual household's "normalized annual consumption" (NAC) for 2 prior years in comparison to the group's average NAC for the same period, and the New Jersey average over a previous 4-year period. The study assumed that consumers would use this information either as a diagnostic tool or as a measure for gauging their consumption relative to others. Respondents were evenly split between those who liked this information and those who did not.

This study concluded that, although consumers exploit a wide array of tools for understanding energy consumption, the monthly bill is the most extensively used. The HER differed from existing bills in having:

- Annual total with monthly breakdowns

- Rate-adjusted dollar figures

- Weather-adjusted consumption rather than daily average temperature or degree days

- Usage breakdowns

- Comparisons with averages.

The investigators suggested that a HER would provide the following:

- Save people the trouble of computing an annual energy total on their own

- Add more valuable comparative information than the unadjusted dollar totals most respondents used for computations 
- Enable people to feel more confident of savings that result from conservation efforts by reliably accounting for weather fluctuations and rate changes

- Separate space heating from other energy uses analytically

- Compare individual usage to neighborhood usage.

Integrating interviews into the design of this study found the HER flawed in two ways:

- Raw monthly data needed to be used.

- Allowance for the fact that most consumers did not understand weather-adjusted consumption was needed.

Summary. The studies including feedback on energy costs, either alone or in combination with information about $\mathrm{kWh}$ consumed, showed that cumulative cost information feedback appeared to be most effective in reducing usage. In two studies with different forms of feedback, customers tended to prefer cumulative information over daily or hourly information. Two studies, both by Bittle, Valesano, and Thaler, resulted in contradictory findings. Both studies provided cumulative feedback on costs and $\mathrm{kWh}$ used, yet one found that higher electricity users conserved more, while the other found that lower-use customers saved more in the feedback condition.

\section{Studies Using Displays}

Four studies were located that used electronic displays in the home as the medium through which feedback on electricity consumption was provided. These were (a) McClelland and Cook (1979-80), (b) Seligman and Darley (1976-77), (c) Kohlenberg, Phillips, and Proctor (1976), and (d) Ramey-Smith and Gagnon (1979). The latter two studies are described in the sections on feedback with incentives and feedback using cost information, respectively.

McClelland and Cook (1979-80) found homes with continuous in-home monitors had lower levels of consumption over an 11-month period than homes without continuous monitors. This study involved 101 all-electric single-family homes in Carrboro, N.C. When built, 25 of the homes were equipped with "Fitch energy monitors," which measured electrical current, translated the current used at any given moment into cents per hour according to a cents per $\mathrm{kWh}$ figure set manually on the device, and displayed this feedback on a digital read-out located on the thermostat.

Carolina Light and Power Company provided utility billing records of electricity consumption for each home from September to July. A multiple regression analysis associated monitors with lower electricity consumption in all 11 months. The homes equipped with monitors averaged $12 \%$ less electricity consumption than those without monitors. The differences neither increased or decreased over time, although they did tend to be larger during months when demands for heating or cooling were lower, suggesting that conservation actions taken by households with monitors primarily affected energy uses other than heating and cooling. The study further suggested that the monitor's greater impact on nonheating and cooling energy uses indicated that the monitors may have served to teach consumers what activities consumed the most energy rather than to call attention to the cost of energy. 
Seligman and Darley (1977) investigated the effects of feedback alone via a Lucite display attached to the outside of the kitchen window in houses located in central New Jersey. Investigators randomly assigned four households, where electricity was used for central air conditioning, lighting, and refrigeration, to either a feedback or a control condition. The study covered a 3-month period from July to September.

Meter readings taken for 5 weeks provided data for predicting each household's future rate of energy usage based on an outdoor temperature. Research staff then read the households' electric meters for 5 days per week over a 3-week period. The participants were told that air conditioning was the largest use of electricity and that it was hoped air conditioning use would ba recuced.

Research staff calculated an actual over predicted electricity consumption ratio for each feedback household and recorded this percentage in the Lucite display 4 times per week for 3 weeks. If the household's predicted performance was to use 10 units of energy and 8 units were actually used, the display read "80\%."

The study revealed that the feedback group used approximately $11 \%$ less electricity during the feedback period than the control group receiving no feedback. This study also found that the level of conservation obtained through feedback was unrelated to the initial level of energy used, suggesting that lower users are as capable of reducing energy consumption as higher users through feedback techniques.

Summary. Three of the studies using digital displays provided feedback on $\mathrm{kWh}$ usage only, not on costs. The fourth displayed cost information. As in the other studies, the feedback condition tended to result in lower electricity consumption. However, the studies offer no evidence that displays are a more effective mode of providing information than notes, cards, utility bills or one-time reports.

\section{Other Related Studies}

Two other studies did not fit within these categories. They were: (a) Winkler and Winett (1982) and (b) Katzev, et al. (1980-81).

Winkler and Winett (1982) performed a meta-analysis on behavioral residential energy conservation studies using feedback in which effects were reported by different household income levels. They found a relationship between energy behavior resulting from feedback and the proportion of the household budget used for energy (electricity or natural gas) needs. This analysis concluded that feedback had little effect in reducing energy consumption in households where energy costs were no more than $2 \%$ of the household budgets. By contrast, people using a larger proportion $(>2 \%)$ of their income for energy were likely to benefit more from a feedback program.

Katzev, Cooper, and Fisher (1980-81) investigated the effects of feedback and social reinforcement during a 7-week summer period on 11 all-electric apartments in a Portland, Oreg., suburb. The study consisted of 2-week baseline, information, and treatment phases and a 1-week follow-up phase.

The study distinguished four groups as follows:

- Control:

Meter readings were taken daily with no intervention given. 


\section{SEP *}

- Daily contingent feedback:

- 3-day contingent feedback plus decal:
Meters were read daily. Feedback sheets comparing the previous days meter reading to the control group's average for the preceding day translated into monetary costs were taped to the door for 14 days.

Meters were read daily. Every third day, feedback sheets covering total usage for the 3 preceding days compared to the control group were taped to the door. When consumption was less than the previous 3-day period, a stick-on decal with the statement "We are conserving energy" was given.

Meters were read daily. Every third day, feedback slips indicating only if they had been successful in reducing energy were taped to the doors. Five decals were given over a 2-week period.

Results indicated that feedback had little or no impact on reducing electrical energy consumption in households receiving feedback compared to households receiving no feedback. Feedback also had little or no impact on feedback households when compared to baseline levels of usage. 


\section{DISCUSSION}

\section{Policy Implications}

The bulk of the literature provides evidence that information feedback can play a role in reducing electricity consumption, on the order of from $5 \%$ to $20 \%$. This variation may be explained by the varying ways in which feedback was provided, varying content of the feedback messages, and the weather at the time the feedback was provided. The studies suggest strongly that:

- Feedback in combination with monetary incentives is most effective.

- Feedback in connection with conservation performance goals may be most effective.

- Feedback in written form is probably more effective than on-site displays.

- Cumulative information is more effective than other forms.

- Cost information or cost plus consumption information is more effective than information on $\mathrm{kWh}$ consumption alone.

Although most of the researchers used feedback methods involving cards, charts, fliers, and notes delivered to the household, such means of providing feedback would not be feasible on a broader scale. The most likely source of feedback information is the customer's utility company. Thus, the findings on feedback should be considered in the light of what utility companies might effectively provide their customers by way of feedback information.

The studies which looked at utility participation in feedback were McClelland and Cook (1979-80), Layne, et al. (1987), and Morgan (1988). None of these studies investigated the difference between utility company and other sources of information feedback. They seem to offer preliminary evidence, however, that electricity consumption can be reduced by the utility company providing feedback information to customers. Further, the evidence in the literature would support the notion that information provided should be on cumulative costs (annually and, perhaps, monthly or seasonally), rather than on $\mathrm{kWh}$ usage, although including both costs and $\mathrm{kWh}$ usage might be best.

A one-time analysis in an annual report rather than a monthly billing might be sufficient to achieve consumption declines. Weather-adjusted information would apparently be useful also. An added benefit to the utility company of providing disaggregated cost information is the resolution of high bill complaints by customers.

\section{Research Needs}

Much of the difficulty in defining the effects of feedback lies in the inability to generalize existing research findings. Even though feedback appears to reduce electricity consumption effectively, the findings are far from convincing. Many questions remain unanswered, such as:

- What types of feedback procedures are best depending on various weather conditions?

- What types of consumers should be targeted for feedback?

- Does the frequency of feedback, such as daily, weekly, monthly, or yearly, impact its effectiveness?

- Does feedback alone provide the desired effects? 
- Does the source of feedback, such as researcher or power company, have a bearing on results?

- Does the form in which feedback is presented, (e.g., written notes, light signals, continuous monitoring devices, conventional meter reading, or weekly/monthly reports) have a bearing on desired effects?

- Does the way in which the feedback is presented, such as absolute kWh usage, percentage of change from baseline levels, actual $\mathrm{kWh}$ usage compared with corrected estimates of usage, or $\mathrm{kWh}$ usage compared with consumption of other individuals, impact its effectiveness?

- Must the desired amount of conservation be defined before feedback effectiveness can be determined?

- To what degree are interested parties, such as consumers, power companies, and government, willing to invest in such conservation techniques?

At the present time, the conditions under which feedback is most effective have not been determined. Also to be determined is the degree of change that feedback techniques could be expected to produce. In addition, the parameters (e.g., source and form of feedback, method of delivery, and period of time it is presented) for determining when, where, and how feedback is effective remain unclear. Finally, follow-up on long-term effects is missing. The longevity effects of feedback once stimuli have been removed or when feedback becomes a routine part of consumers' lives remains unexplored.

In short, the effectiveness of feedback in promoting electricity conservation must be viewed cautiously. Before feedback as a conservation technique can be employed with greater confidence, the parameters of influence should be defined adequately. Without such definition, generalizations on the impacts of such techniques cannot be formulated accurately. 


\section{REFERENCES}

Becker, Lawrence J. (1978). "Joint Effect of Feedback and Goal Setting on Performance: A Field Study of Residential Energy Conservation." Journal of Applied Psychology 63:428-433.

Bittle, Ronald G., Robert Valesano, and Greg Thaler (1979). "The Effects of Daily Cost Feedback on Residential Electricity Consumption." Behavior Modification 3:187-201.

Bittle, Ronald G., Robert Valesano, and Greg Thaler (1979-80). "The Effects of Daily Feedback on Residential Electricity Usage As A Function of Usage Level and Type of Feedback Information." Journal of Environmental Systems 9:275-287.

Hayes, Steven C. and John D. Cone (1977). "Reducing Residential Electrical Energy Use: Payments, Information, and Feedback." Journal of Applied Behavior Analysis 10:425-435.

Katzev, Richard, Laura Cooper, and Pat Fisher (1980-81). "The Effect of Feedback and Social Reinforcement on Residential Electricity Consumption." Journal of Environmental Systems 10:215-227.

Kempton, W. and L. L. Layne (1988). "The Consumer's Energy Information Environment." Behavior and Lifestyle, Proceedings of the 1988 Summer Study on Energy Efficiency in Buildings II:11.51-11.66.

Kohlenberg, Robert, Thomas Phillips, and William Proctor (1976). "A Behavioral Analysis of Peaking in Residential Electrical-Energy Consumers." Journal of Applied Behavior Analysis 9:13-18.

Layne, L., W. Kempton, A. Behrens, R. Diamond, M. Fels, and C. Reynolds, (CEES) (1987). "Design Criteria For A Consumer Energy Report: A Pilot Field Study." Unpublished. Princeton University.

McClelland, Lou and Stuart W. Cook (1979-80). "Energy Conservation Effects of Continuous In-Home Feedback In All-Electric Homes." Journal of Environmental Systems 9:169-173.

Morgan, Stephen J. (1988). "Evaluation of the Boston Edison Company 'EASY-Plus' Disaggregated Utility Electric Usage Analysis," in Innovative Energy Programs for Homes: Two Case Studies, (final draft) Barbara C. Farhar (ed.), Golden, CO: Solar Energy Research Institute.

Palmer, Michael H., Margaret E. Lloyd, and Kenneth E. Lloyd (1977). "An Experimental Analysis of Electricity Conservation Procedures." Journal of Applied Behavior Analysis 10:665-671.

Ramey-Smith, Ann and Jennifer L. Gagnon (1979). "An Investigation of Preferences for Various Types of Energy Cost Feedback." U.S. Department of Energy Report No. NBSIR 79-1771.

Seligman, Clive and John M. Darley (1977). "Feedback as a Means of Decreasing Residential Energy Consumption." Journal of Applied Psychology 62:363-368. 
Winett, Richard A., John H. Kagel, Raymond C. Battalio, and Robin C. Winkler (1978). "Effects of Monetary Rebates, Feedback, and Information on Residential Electricity Conservation." Journal of Applied Psychology 63:73-80.

Winett, Richard A., Stephen Kaiser, and Gerald Haberkorn (1976-77). "The Effects of Monetary Rebates and Daily Feedback on Electricity Consumption." Journal of Environmental Systems 6:329-341.

Winett, Richard A., Michael S. Neale, and H. Cannon Grier (1979). "Effects of SelfMonitoring and Feedback on Electricity Consumption." Journal of Applied Behavior Analysis 12:173-184.

Winett, Richard A., Michael S. Neale, Kenneth Williams, James Yokley, and Hugh Kauder (1978-79). "The Effects of Feedback on Residential Electricity Consumption: Three Replications." Journal of Environmental Systems 8:217-233.

Winett, Richard A., Joseph W. Hatcher, T. Richard Fort, Ingrid N. Leckliter, Susan Q. Love, Anne W. Riley, and James F. Fishback (1982). "The Effects of Videotape Modeling and Daily Feedback on Residential Electricity Conservation, Home Temperature and Humidity, Perceived Comfort, and Clothing Worn: Winter and Summer." Journal of Applied Behavioral Analysis 15(3):381-402.

Winkler, Robin C., and Richard A. Winett (1982). "Behavioral Interventions in Resource Conservation." American Psychologist 37:421-435. 


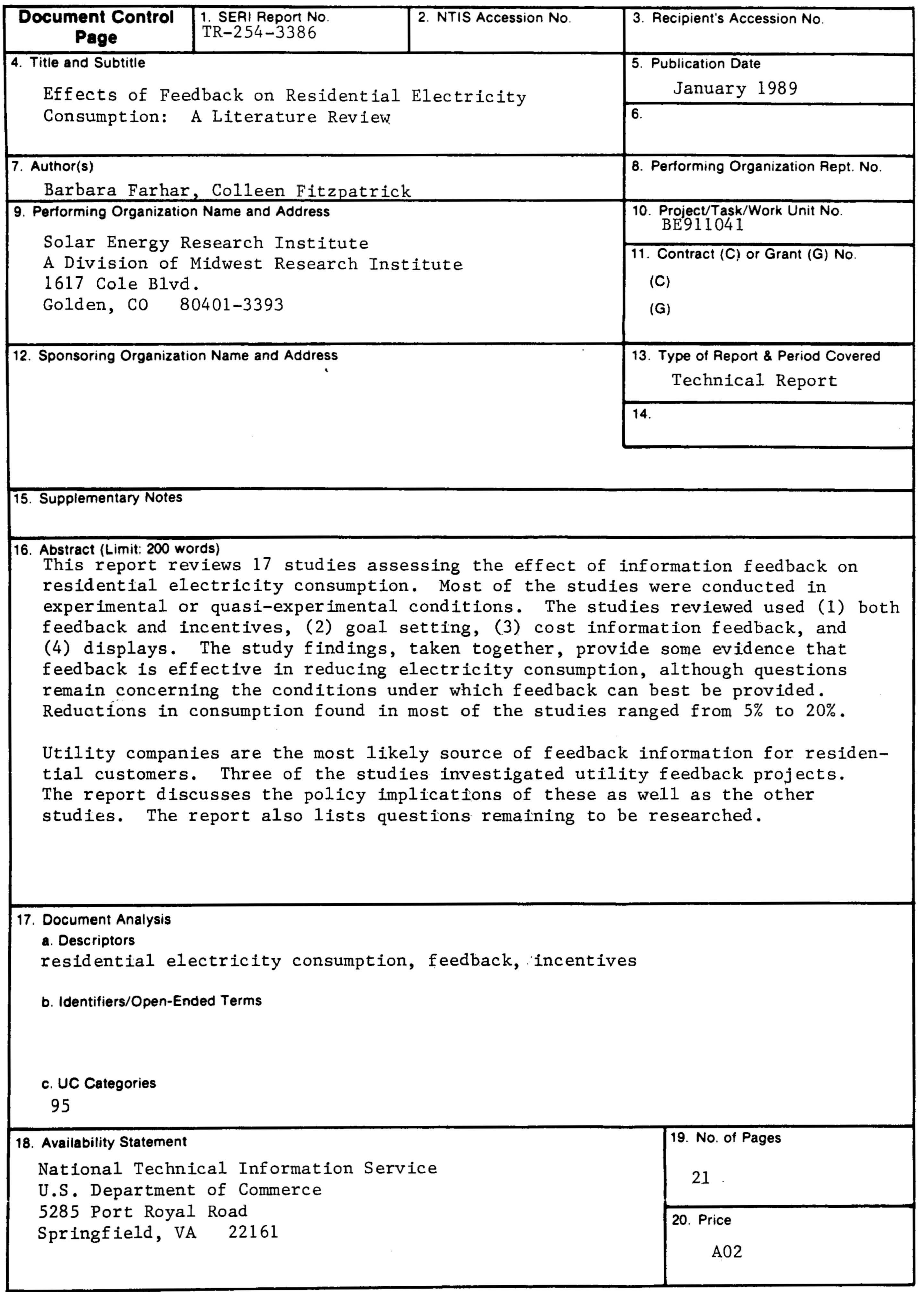

